\title{
Ultrastructural Evolution of the Corona Radiata Follicular Cells
}

\author{
Elsa B. Schuchner and Juan C. Stockert \\ Centro de Investigaciones en Reproducción, Facultad de Medicina, \\ Buenos Aires, Argentina
}

Received September 12, 1972

The follicular cells of the corona radiata surround the mammalian oocyte since its development in the ovary until the tubal passage. These cells arise from the follicular cells of the primordial follicle and belong to a particular cell population that presents several characteristics, such as a short life-span and a special association with the oocyte, which permit an approach to the phenomena of cell differentiation and degeneration.

The morphological changes of the cells of the corona radiata after ovulation have been scarcely studied. The aim of this work is to present some ultrastructural observations on the involution of the rat corona radiata cells.

\section{Material and methods}

Vaginal smears of albino rats were checked for two weeks for normal cycling, and those rats on proestrous were caged with males of proven fertility. According to previous experiments the rats of our colony ovulate between 4 a.m. and 6 a.m. Sperm was checked by vaginal smears. Animals were sacrificed at different timing before and after ovulation. At sacrifice the genital tract was removed "in toto" and the Fallopian tubes were placed in a watch glass. Under a dissecting microscope, the eggs were flushed from the tubes with $0.2 \mathrm{ml}$ of $2.5 \%$ glutaraldehyde in $0.2 \mathrm{M}$ phosphate buffer at $\mathrm{pH} 6.8$ by means of a $0.25 \mathrm{ml}$ syringe and a 30 -gauge needle. Eggs were kept in the same fixative at $4^{\circ} \mathrm{C}$ for 1.5 hours. They were then washed with phosphate buffer containing $0.1 \mathrm{M}$ sucrose and postfixed with Caulfield's osmium fixative for 1 hour at $4^{\circ} \mathrm{C}$. After washing in distilled water, the eggs were embbeded in agar (Samuel 1944) to facilitate further manipulation, dehydrated in increasing alcohol concentrations and finally embedded in Maraglas. Ovarian pieces from adult normal rats were processed similarly. Thin sections were obtained in a Porter Blum microtome and observed in a Elmiskop I electron microscope, after staining with uranyl acetate and lead citrate. Thick sections were stained with Unna's blue and studied with the light microscope.

\section{Results}

Very few mitotic divisions occur in the oocyte-surrounding cells, either in the

1 Address: Centro de Investigaciones en Reproducción, Facultad de Medicina, Paraguay $2155-10^{\circ}$ Piso, Buenos Aires, Argentina. 


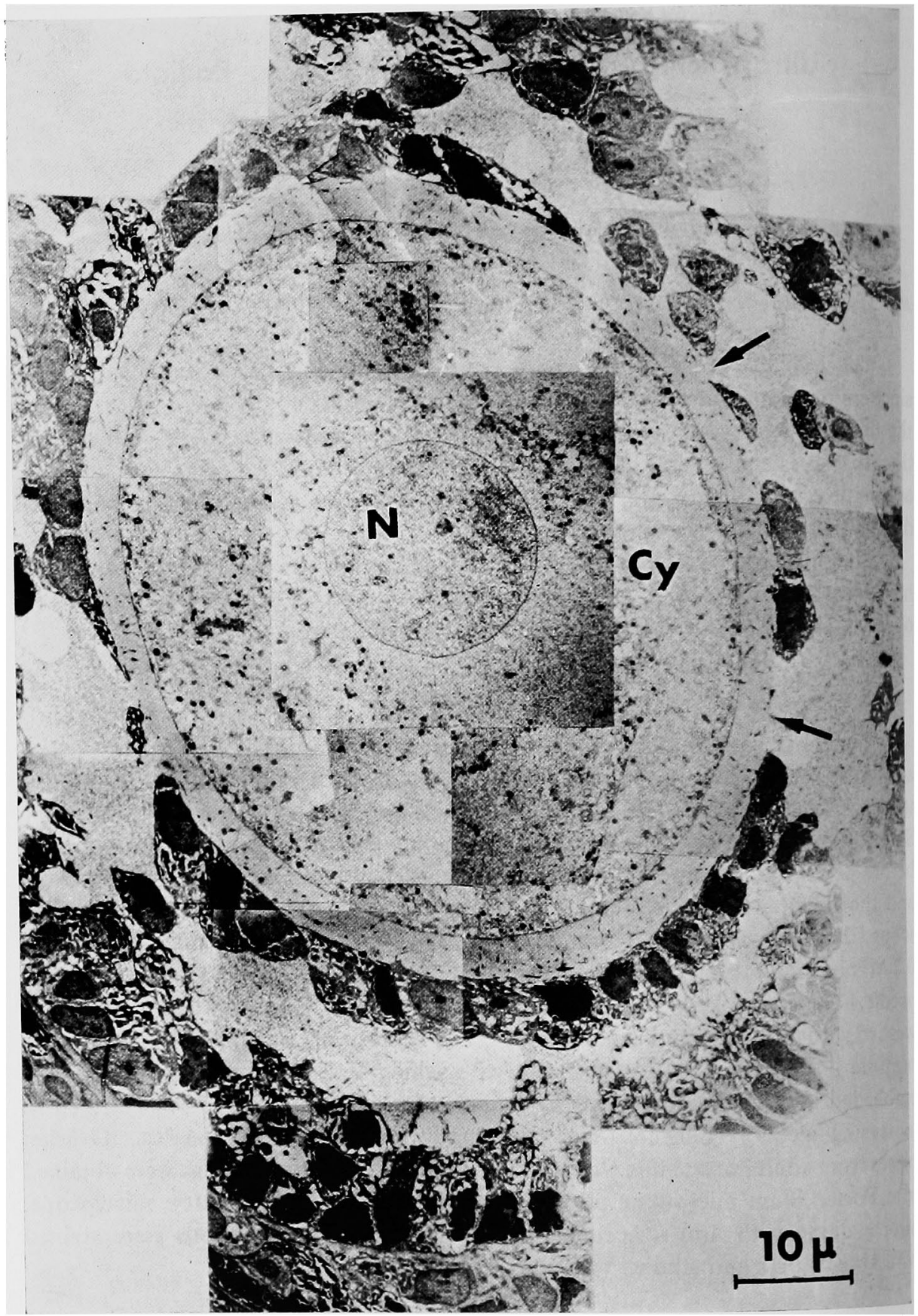

Fig. 1. Panoramic reconstruction of a growing follicle. Notice the absence of follicular cells in some areas (arrows). $\mathrm{N}$ : oocyte nucleus; Cy: oocyte cytoplasm. $\times 1670$. 
growing or in the Graaphian follicles as shown by serial thick sections of the rat ovary. On the contrary divisions are frequently found in the follicular cells which are proximal to the basal membrane of the growing follicle.

The follicular cells that surround the growing oocyte forming a discontinuous layer, present an irregular shape and leave between them some empty spaces in which the follicular fluid contacts with the pellucida membrane (Fig. 1). During advanced periods of the growing follicle as well as by ovulation time (Fig. 2a) these follicular cells show an ultrastructural morphology similar to the cells of undeveloped follicles, presenting an irregular nucleus (about $4.5 \mu$ in diameter) with areas of condensed chromatin attached to the inner sheet of the nuclear envelope or dispersed in the nucleus (Fig. 2b). One or two nucleoli and interchromatinic spaces occupied by fibrillar and granular elements (perichromatin fibrils, interchromatin and some perichromatin granules) can be generally observed. The nucleolus shows in most cases a reticular structure but sometimes it appears more compacted. Its constitutive elements are fibrillar and granular components arranged often as discontinuous, thread-like structures, and some light fibrillar areas ("fibrillar centers", Recher et al. 1969).

At the time of ovulation each oocyte is surrounded by a single and in some areas by a double layer of follicular cells. This second layer is usually incomplete and discontinuous. The cytoplasm of the corona radiata cells protruded into the pellucida membrane as dense and irregular multibranched projections (about $0.13 \mu$ in diameter) which are in close contact with the oocyte microvilli. This polarity of the follicular cells develops in the growing follicule before apparition of the pellucida membrane. Each follicular cell shows three or four projections that interconnect (in some cases by tight junctions or desmosomes) with one or several microvilli.

About 2-4 hours after ovulation (animals which were sacrificed at 8 a.m.) the first signs of the withdrawal of the corona radiata cells from the oocyte can be observed (Fig. 3). The cytoplasmic projections are no longer in close contact with the microvilli, but they still remain in the peripheral regions of the pellucida membrane. The ultrastructural morphology of this membrane does not reveal any apparent modification, but the follicular projections show a less dense cytoplasm than in the previous period, as well as a scarce neatness of their membranes.

About 10-12 hours after ovulation the pellucida membrane is free of follicular projections, and empty spaces between the microvilli and the pellucida membrane can be seen (Figs. 4a, b, and c). The attachment between follicular cells (so tight in the corona radiata) no longer exists and wide areas of the pellucida zone are free of follicular cells. Some traces of the projections can still be seen in connection with the pellucida (Figs. $4 \mathrm{~b}$ and c). As a clear sign of involution the organelles of the follicular cells begin to manifest several morphologic alterations. Mitochondria show different degrees of swelling, and the endoplasmic reticulum and Golgi apparatus present blurred edges. Small vacuoles, apparently arising from the smooth endoplasmic reticulum, appear in the cytoplasm. At this stage, nuclei usually reveal several patches of condensed chromatin attached to the nuclear envelope. 

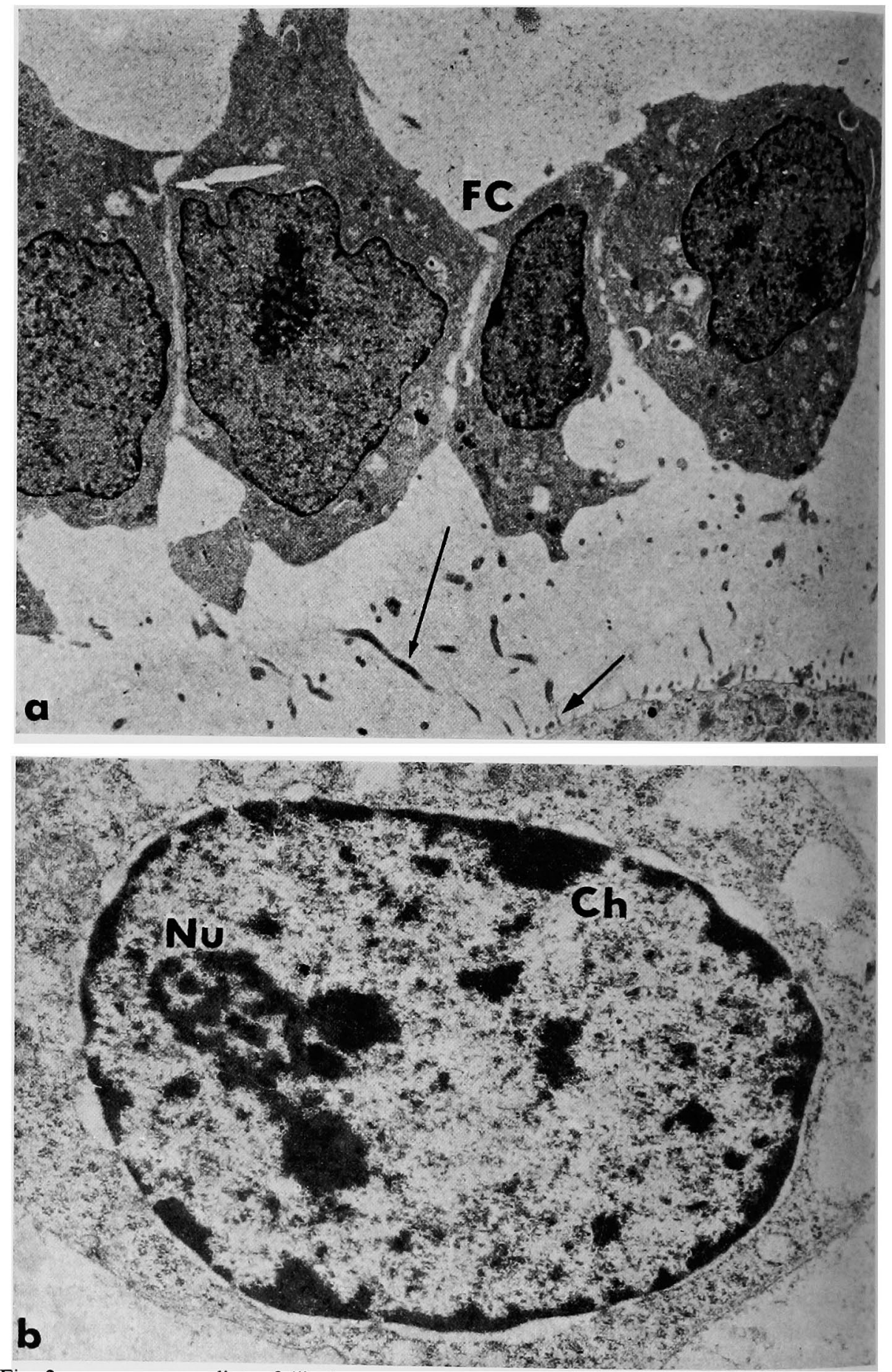

Fig. 2. a, corona radiata follicular cells (FC) by ovulation time. Follicular projections (long arrow) and microvilli (short arrow) within the pellucida membrane can be seen. $\times 7780$. b, nucleus of a follicular cell. Nu: nucleolus; Ch: chromatin. $\times 32000$. 


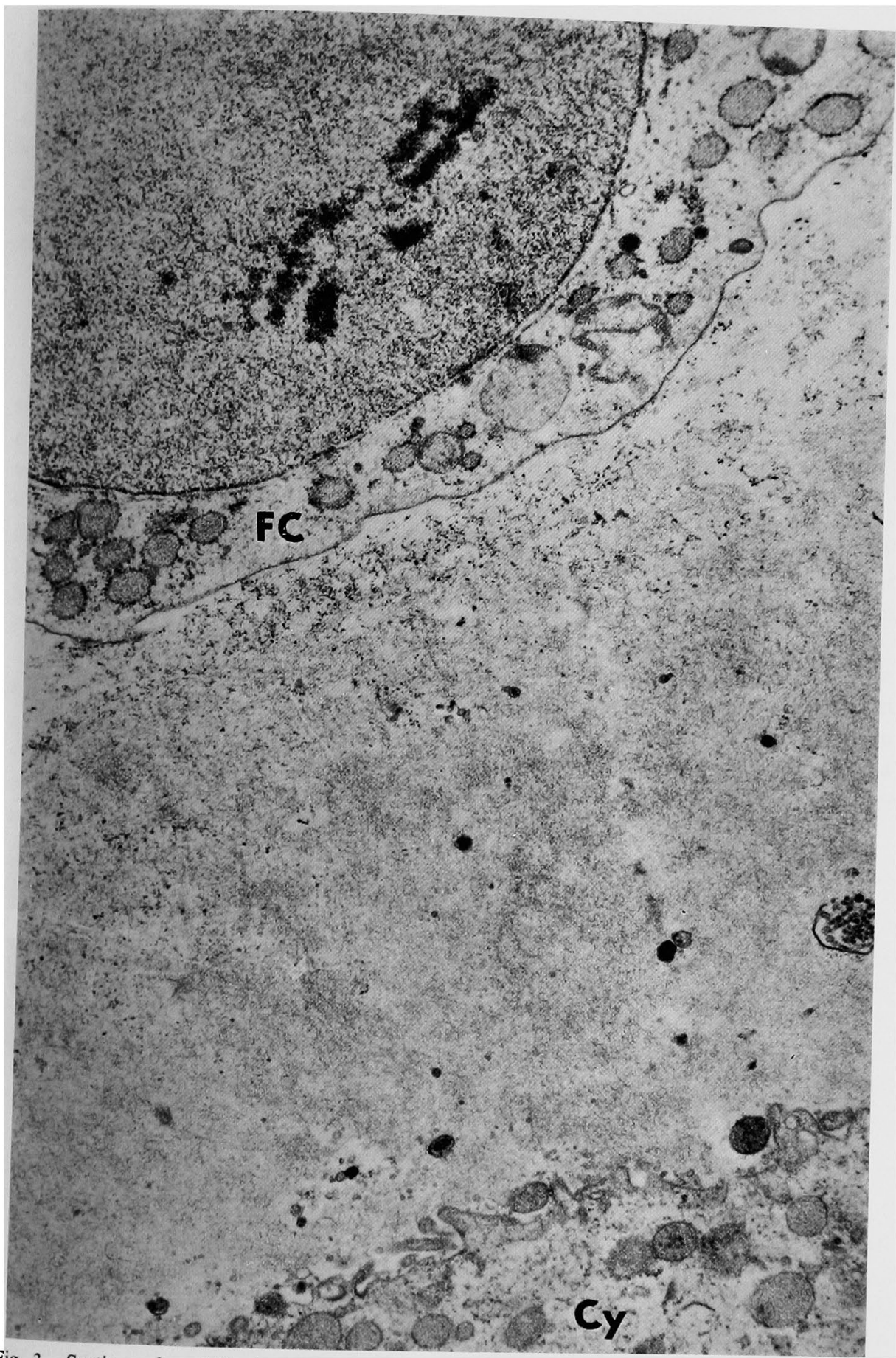

Fig. 3. Section of a follicular cell of the corona radiata (FC) two hours after ovulation. Cy: oocyte cytoplasm. $\quad \times 28000$. 

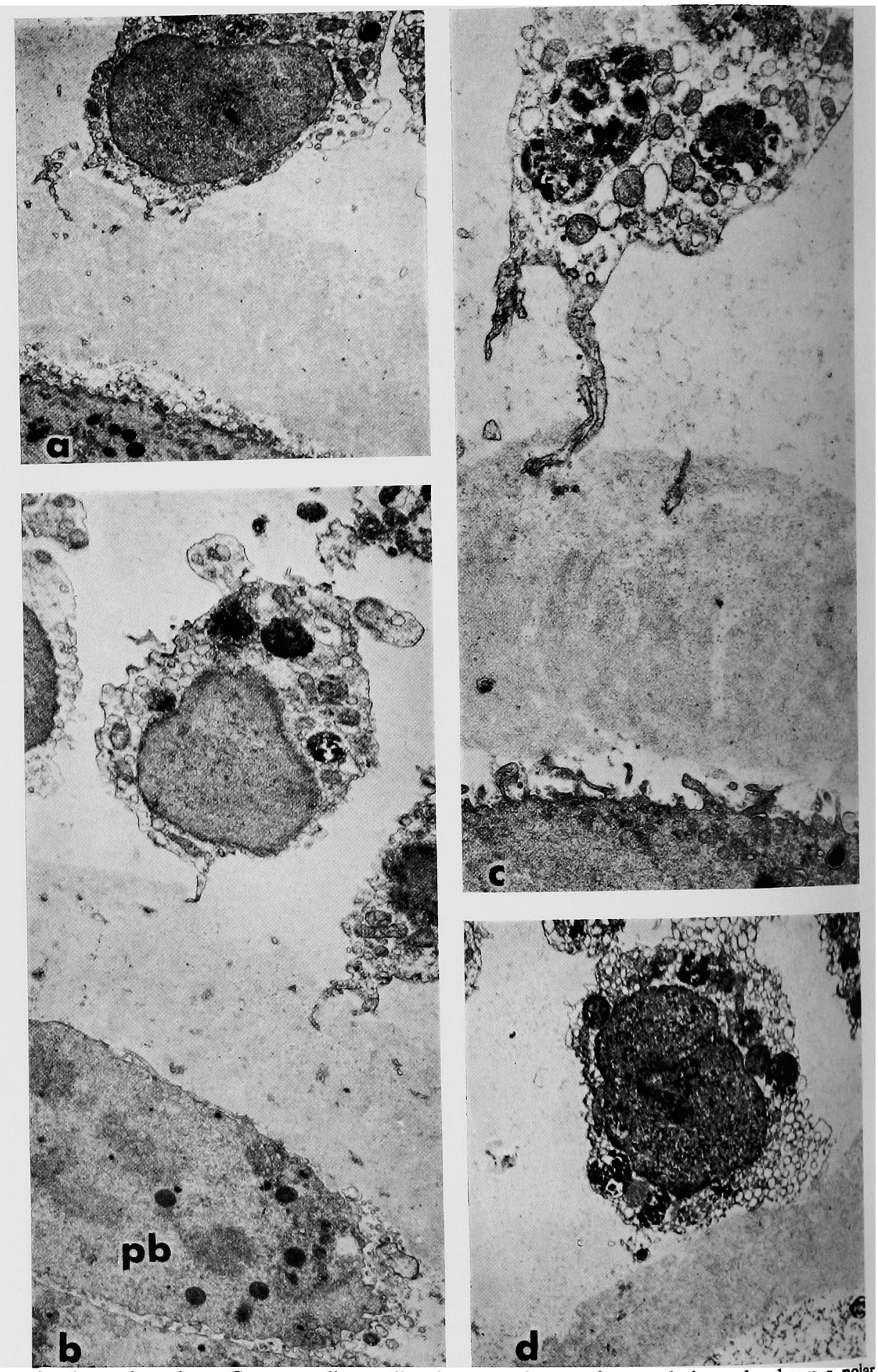

Fig. 4. a, b and c. Corona radiata cells about ten hours after ovulation. b, shows a polar body $(\mathrm{pb})$. d, eighteen hours after ovulation. 
Eighteen-twenty hours after ovulation, the remnants of the corona radiata are constituted by a few follicular cells with severe signs of damage (Fig. 4d). Small nuclei with an homogenous inner structure, and very small and extremely dense nucleoli composed of tightly packed fibrils, are observed. These cells show a vacuolized cytoplasm where organelles are difficult to identify. In addition, dense bodies with morphological features of lysosomes and vacuolated structures containing heterogenous and small dense bodies (autophagic vacuoles?) can often be observed in the cytoplasm of the corona radiata cells during this stage of involution.

\section{Discussion}

The existence of empty spaces between the follicular cells of the corona radiata seems to have been overlooked by previous workers (Chiquoine 1959, 1960, Sotelo and Porter 1959, Zamboni and Mastroianni 1966, Zamboni et al. 1966). These spaces, that do not necessarily implicate new interchanges between the vitellus and the follicular fluid, could originate from the great increase of the volume of the growing oocyte. According to Austin (1951) this volume increases about 90 times during mammalian oogenesis. Even assuming the displacement of other follicular cells to the corona radiata, the pellucida zone would probably remain incompletely surrounded (see Fig. 1).

Ribosomal RNA synthesis start during the second day of tubal life both in fertilized and unfertilized eggs (Flax 1953, Mintz 1965). According to the present and earlier observations (Schuchner 1970) the beginning of the RNA and protein synthesis seems to coincide with the complete involution of the corona radiata cells, and this involution is probably related to the development of the oocyte autonomy.

\section{Summary}

The follicular cells of the corona radiata surround the rat oocyte from the stage of growing follicle. They are arranged as a discontinuous layer, leaving some empty spaces. About 10-12 hours after ovulation, the cells of the corona radiata begin a rapid process of involution showing the disappearance of the cytoplasmic projections as well as ultrastructural alteration of the organelles. By the end of the first day of tubal life, signs of severe damage are evident in the few remaining cells.

\section{Acknowledgements}

The authors wish to express their thanks to Miss A. Paczy for her technical assistance and to Dr. J. A. Lisanti for reading the manuscript. This work was supported by grants from "The Population Council", New York (71/104 C) and from the Consejo Nacional de Investigaciones Científicas y Técnicas (4840/71) Argentine. 


\section{Literature}

Austin, C. R. 1951. The formation, growth and conjugation of the pronuclei in the rat egg. J. R. Micr. Soc. 71 : 295-306.

Chiquoine, A. D. 1959. Electron microscopic observations on the developmental cytology of the mammalian ovum. Anat. Rec. 133: 258.

- 1960. The development of the zona pellucida of the mammalian ovum. Am. J. Anat. 5: 149-169.

Flax, M. H. 1953. Ribose nucleic acid and protein during oogeneis and early embryonic development in the mouse. Ph.D. Thesis, Columbia University.

Mintz, B. 1965. Nucleic acid and protein synthesis in the developing mouse embryo. In "Preimplantation Stages of Pregnancy" Ed. C. E. W. Woltenholme: 145-183.

Recher, L., Withescarver, J. and Griggs, L. 1969. The fine structure of a nucleolar constituent. J. Ultrastruct. Res. 29: 1-14.

Samuel, D. M. 1944. The use of an agar gel in the sectioning of mammalian egg. J. Anat. (London) 78: 173-175.

Schuchner, E. B. 1970. Ultrastructural changes of the nucleoli during early development of fertilized rat eggs. Biol. Reprod. 3: 265-274.

Sotelo, J. R. and Porter, K. R. 1959. An electron microscope study of the cytoplasmic and nuclear component of rat primary oocyte. J. Biochem. Biophys. Cytol. 5: 327-341.

Zamboni, L. and Mastroianni, L. 1966. Electron microscopic studies on rabbit ova II. The penetrated tubal ovum. J. Ultrastruct. Res. 14: 118-132.

— , Mishell, D. R., Bell, J. H. and Baca, M. 1966. Fine structure of the human ovum in the pronuclear stage. J. Cell. Biol. 3: 579-600. 